\title{
SOLID-LIQUID INTERFACE MORPHOLOGY OF WHITE CARBIDE EUTECTIC DURING DIRECTIONAL SOLIDIFICATION
}

\begin{abstract}
In this paper the analysis of solid-liquid interface morphology in white carbide eutectic was made. In a vacuum Bridgman-type furnace, under an argon atmosphere, directionally solidified sample of $\mathrm{Fe}-\mathrm{C}$ alloy was produced. The pulling rate was $v=125 \mu \mathrm{m} / \mathrm{s}$ $(450 \mathrm{~mm} / \mathrm{h})$ and constant temperature gradient $G=33.5 \mathrm{~K} / \mathrm{mm}$. The microstructure of the sample was frozen. The microstructure of the sample was examined on the longitudinal section using an light microscope and scanning electron microscope.

Keywords: solid-liquid interface, directional solidification, front solidification, white carbide eutectic
\end{abstract}

\section{Introduction}

One of the most common solidification patterns in the binary or multi-component alloy systems are eutectic microstructures. The mechanical properties of the castings might improve in commercial applications of the eutectic alloys as a result of the fine periodic microstructures of the eutectic alloys.

The research on the basic solidification theory [1-4] use directional solidification technique. V.L. Davies [5] was first to show the role of leading phases in eutectics [6-10] reveal the theoretical studies of solid-liquid interface formation during oriented eutectic growth.

Generally crystals of non-metals grow with faceted surface, while crystals of metals grow with non-faceted surface. For that reason, dendritic and cellular morphology of a solidifying solid-liquid interface is an important feature of metal solidification. It is responsible for the typical metal microstructures and defects. It leads to the fact of important influence of these flaws on mechanical properties of metals and alloys. Nevertheless, because of the opacity of metallic materials, usually it is very difficult to conduct experimental study on the morphological details of a solidifying solid-liquid interface [11].

Beside the directional solidification associated with a planar solid-liquid interface, it is quite obvious that any protuberance or perturbation at this interface will result in some growth variance. A defect, variation in composition, or variations in the thermal gradient might induce that. One of the most noteworthy of these solidification phenomena is dendritic solidification in its various forms. Usually it is a consequence of rapid solidification [12].

Figure 1 shows solid phases $\alpha$ and $\beta$, as represented in the binary eutectic phase diagram, simultaneously solidify from the

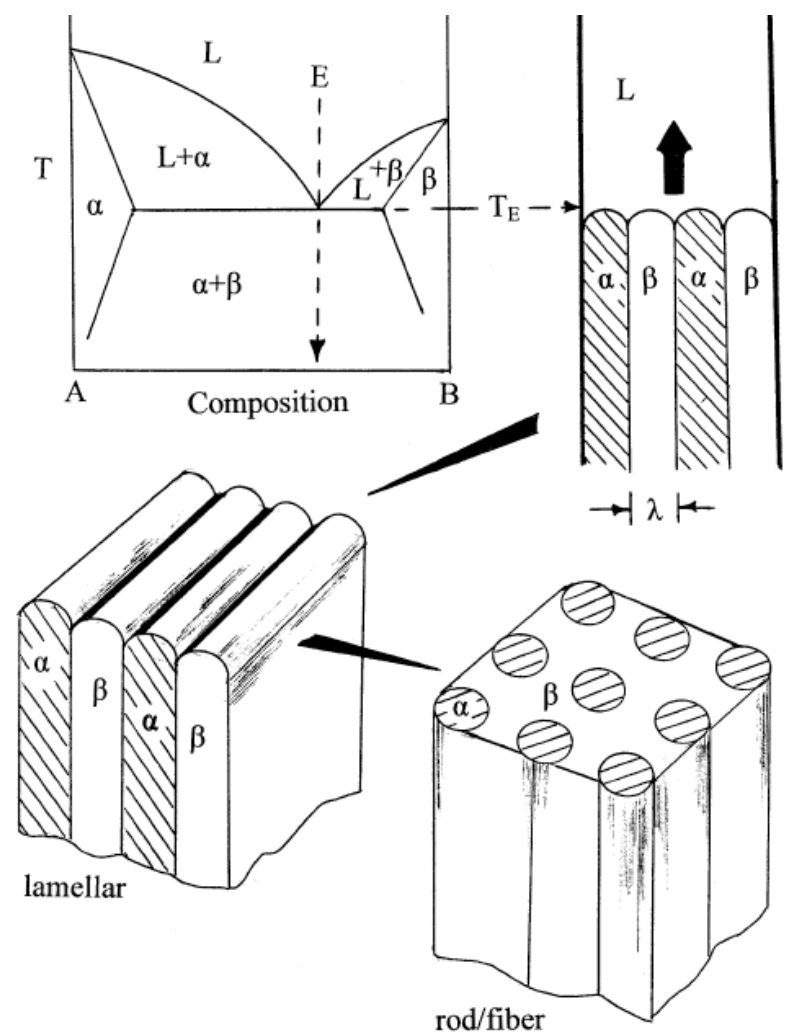

Fig. 1. Eutectic phase diagram (left) and associated unidirectional eutectic phase solidification schematics. $\mathrm{L}$ - liquid; $\alpha, \beta$ - solid phases. $\mathrm{T}_{\mathrm{E}}$ is the eutectic (E) invariant point temperature [12]

liquid L. An aligned, two-phase solid is created by solidification in the direction of the arrow. This two-phase, unidirectional eutectic composite can be lamellar or fiber form. It depends on the growth conditions and total free energy minimization. This 


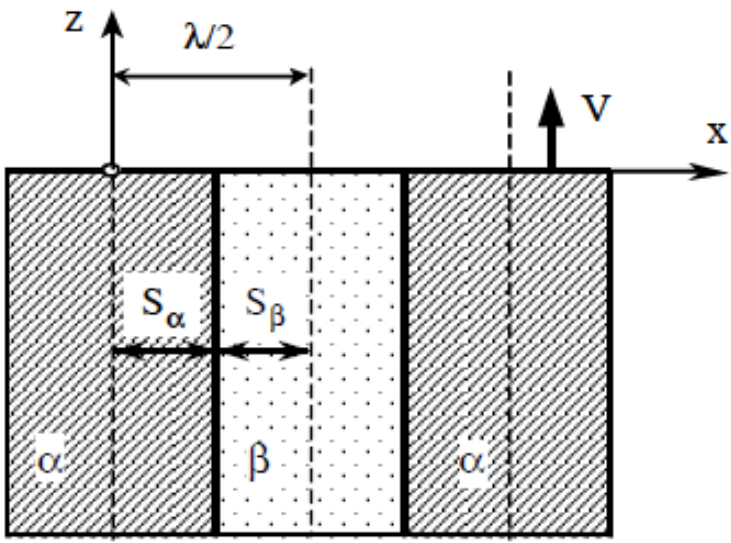

a)

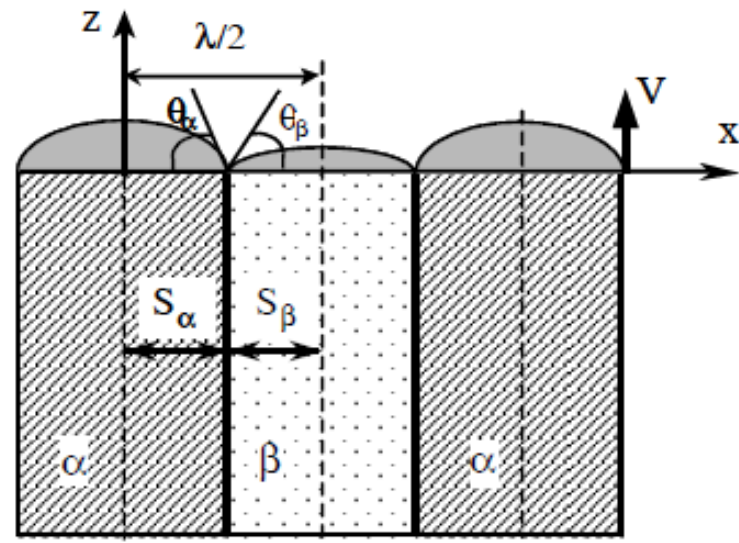

b)

Fig. 2. The eutectic interface geometry: a) the simplified planar s/l interface, b) the real solid shaded areas account for the interface curvature [14]

normally drives the lamellar-to-fiber transition illustrated in the schematic sequence.

The major solidification parameters involve the thermal gradient at the liquid-solid interface and the growth or solidification rate or the velocity at which the liquid-solid interface advances [12].

The Jackson and Hunt [13] classical treatment of the binary eutectic growth starts with solving the solute diffusion equation in front of a planar solid-liquid ( $\mathrm{s} / \mathrm{l}$ ) interface moving at a constant velocity $v$, in the $z$-direction. A plane interface, with $S_{\alpha}$ and $S_{\beta}$ respectively half the widths of $\alpha$ and $\beta$ phases show Figure 2 [14].

The morphology of solidification front in white carbide eutectic during directional solidification was chosen for further studies.

\section{Experimental procedure}

The $\mathrm{Fe}-\mathrm{C}$ sample was prepared from Armco and pressed graphite of spectral purity $99.99 \% \mathrm{C}$ in a corundum crucible under the protection of argon gas in Balzers-type heater. After dross removal and homogenization, the molten alloy was poured into permanent mold and cast into rod $12 \mathrm{~mm}$ in diameter. The specimen was then machined to approximately $5 \mathrm{~mm}$ in diameter using a wire cutting process because of the high brittleness of the metals at this composition. The chemical composition of this alloy is presented in Table 1. The sample was positioned in a alunde tube with an inner diameter of $6 \mathrm{~mm}$ at the center of the vacuum Bridgman-type furnace. Under an argon atmosphere, the sample was heated to a temperature of $1450^{\circ} \mathrm{C}$. After stabilizing the thermal conditions, the sample was lowered at a given rate from the heating part to the cooling part of the furnace, with liquid metal used as the coolant. The sample was grown by pulling it downwards at a constant pulling rate $v=125 \mu \mathrm{m} / \mathrm{s}(450 \mathrm{~mm} / \mathrm{h})$ and at a constant temperature gradient $G=33.5 \mathrm{~K} / \mathrm{mm}$ by means of motor. This is described in more detail in [15]. After the sample was moved by $2 / 3$ of its length it was frozen. The aim was to capture solid-liquid interface morphology in carbide eutectic during directional solidification.
The directional solidification was performed in the Faculty of Foundry Engineering at the AGH University of Science and Technology in Cracow.

TABLE 1

Chemical composition of Fe-C alloy

\begin{tabular}{|c|c|c|c|c|c|}
\hline \hline \multicolumn{7}{|c|}{ Chemical composition, wt. \% } \\
\hline $\mathrm{C}$ & $\mathrm{Si}$ & $\mathrm{Mn}$ & $\mathrm{P}$ & $\mathrm{S}$ & $\mathrm{Cr}$ \\
4.25 & 0.057 & 0.64 & 0.0079 & 0.021 & 0.033 \\
\hline $\mathrm{Ni}$ & $\mathrm{Mo}$ & $\mathrm{Al}$ & $\mathrm{Cu}$ & $\mathrm{Co}$ & $\mathrm{Ti}$ \\
0.0093 & $<0.0020$ & 0.011 & 0.032 & 0.0024 & $<0.0010$ \\
\hline $\mathrm{Nb}$ & $\mathrm{V}$ & $\mathrm{W}$ & $\mathrm{Pb}$ & $\mathrm{Mg}$ & $\mathrm{B}$ \\
$<0.0040$ & 0.0022 & $<0.010$ & $<0.0030$ & $<0.0010$ & 0.0009 \\
\hline $\mathrm{Nb}$ & $\mathrm{V}$ & $\mathrm{W}$ & $\mathrm{Pb}$ & $\mathrm{Mg}$ & $\mathrm{B}$ \\
$<0.0040$ & 0.0022 & $<0.010$ & $<0.0030$ & $<0.0010$ & 0.0009 \\
\hline $\mathrm{Sn}$ & $\mathrm{Zn}$ & $\mathrm{As}$ & $\mathrm{Bi}$ & $\mathrm{Ca}$ & $\mathrm{Ce}$ \\
0.0061 & $<0.0020$ & 0.0069 & $<0.0020$ & 0.0005 & $<0.0030$ \\
\hline $\mathrm{Zr}$ & $\mathrm{La}$ & $\mathrm{Fe}$ & & & \\
0.0043 & 0.0013 & 94.9 & & & \\
\hline \multicolumn{7}{|c|}{}
\end{tabular}

\section{Results and discussion}

After being mechanically ground, polished and etched using Nital solution ( $3 \%$ solution of $\mathrm{HNO}_{3}$ in ethanol) the microstructure of the sample was examined using a light microscope. The microstructure of sample was photographed on the longitudinal section.

The images of microstructure were acquired with Nikon MA100 light microscope, equipped with Zeiss Erc5s digital camera. For detailed analysis of microstructure JOEL JSM 5600 scanning electron microscope was used. Figure 3 shows polished and etched sample with marked growth direction.

The solid-liquid interface morphology of eutectic is presented on Figure 4. Interface shape during oriented eutectic growth was observed. In this Figure, showing the solid-liquid interface morphology, the sample have diameter of $5 \mathrm{~mm}$.

Figure 5 presents a more detailed view of solid-liquid interface. 


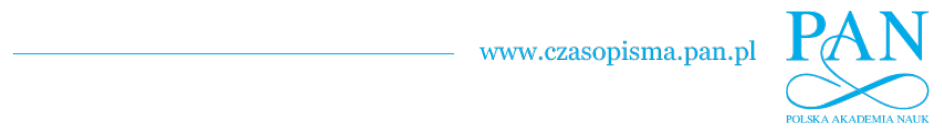

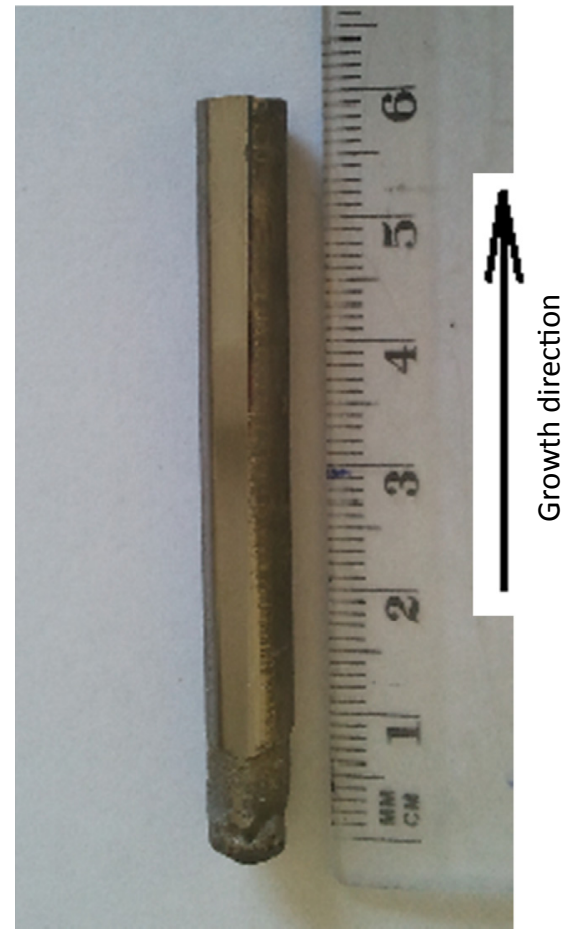

Fig. 3. The image of the research sample
As a result of freezing the sample clear boundary line, separating a solid phase - in the lower part of the figure and liquid phase - in the upper part, was revealed on the longitudinal section (Fig. 4).

The directional solidification resulted in forming of vertical and parallel branches in $\mathrm{Fe}_{3} \mathrm{C}$ iron carbide [16], as Figure 5 shows (bright precipitations). They set the interface shape. The shape of solid-liquid interface of examined sample (Fig. 4) is assumed to be planar. Deviation of interface shape from the planar interface were observed. The shape of interface in the sample is curved and convex.

Figure 6 shows SEM micrograph of white carbide eutectic during directional solidification. The SEM microstructure analysis indicated that branching points of parallel iron carbide fibres are not arranged linearly but in sinusoidal-like order. This arrangement is marked with a line on Figure $6 \mathrm{~b}$. The Figure $6 \mathrm{~b}$ clearly shows leading one of the phases. It is $\mathrm{Fe}_{3} \mathrm{C}$ iron carbide phase.

Figure $6 \mathrm{c}$ shows schema of the contact angles at three-phase junctions. They are different for angle of iron carbide $\theta_{\text {iron carbide }}$ and for angle of austenite $\theta \gamma$. On the SEM micrograph, fine flake structure was observed between parallel, vertical precipitates

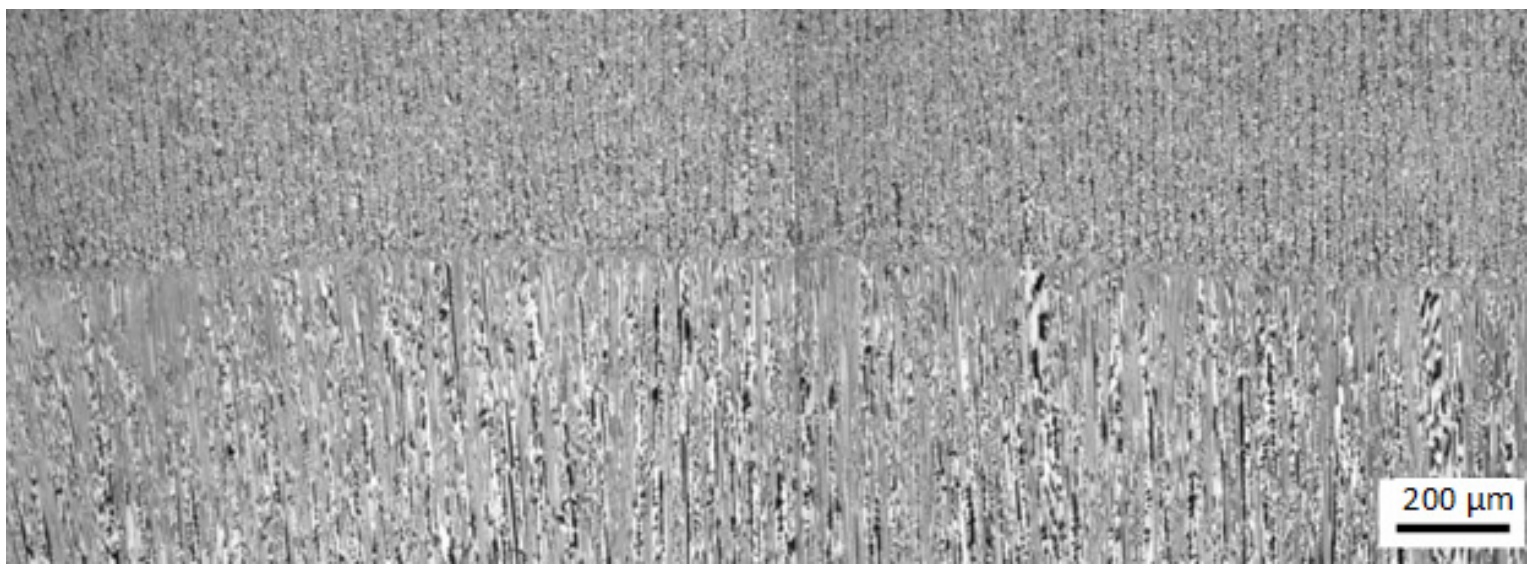

Fig. 4. Solid-liquid interface morphology in sample of diameter $5 \mathrm{~mm}$

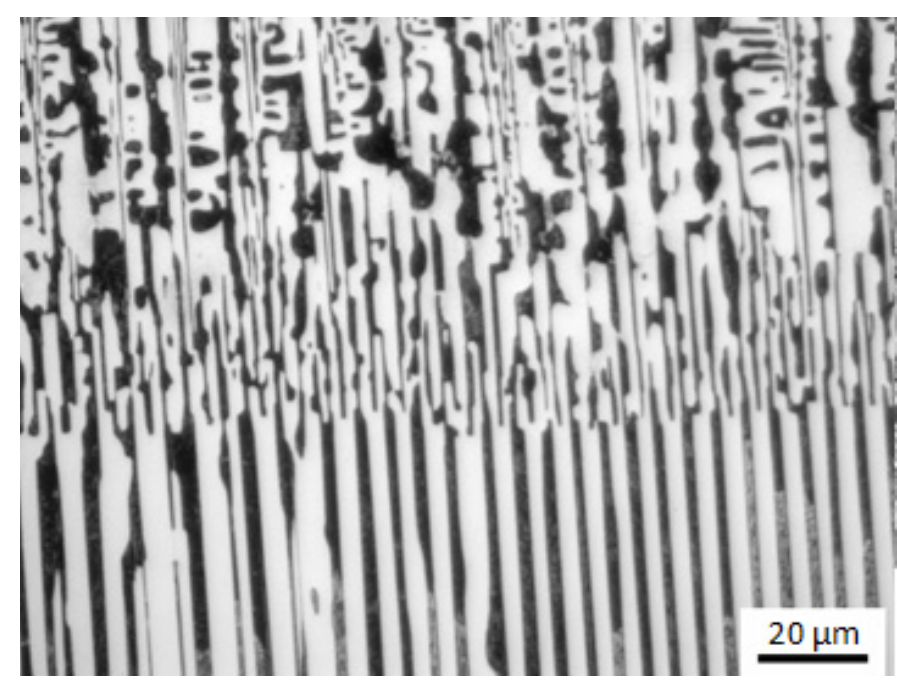

Fig. 5. Longitudinal microstructure of white carbide eutectic, $v=125 \mu \mathrm{m} / \mathrm{s}, G=33.5 \mathrm{~K} / \mathrm{mm}$, light microscope
$\mathrm{Fe}_{3} \mathrm{C}$ iron carbide. In the EBSD measurements, this microstructure has been identified as iron alpha [16]. However, this is inconsistent with the microscopic image of SEM.

\section{Conclusions}

Experimental study on the morphological details of a solidifying solid-liquid interface is usually very difficult because of the opacity of metallic materials. In this work the freezing microstructure method was chosen. Conducted studies show that solid-liquid interface in sample of white carbide eutectic of $5 \mathrm{~mm}$ diameter is planar. But there are also visible areas, where on solidification front of carbide eutectic protrusion occurs (Fig. 5). In directional solidification of white carbide eutectic occurrence of leading phase was revealed. That leading phase was proved to be the $\mathrm{Fe}_{3} \mathrm{C}$ iron carbide phase. 
a)

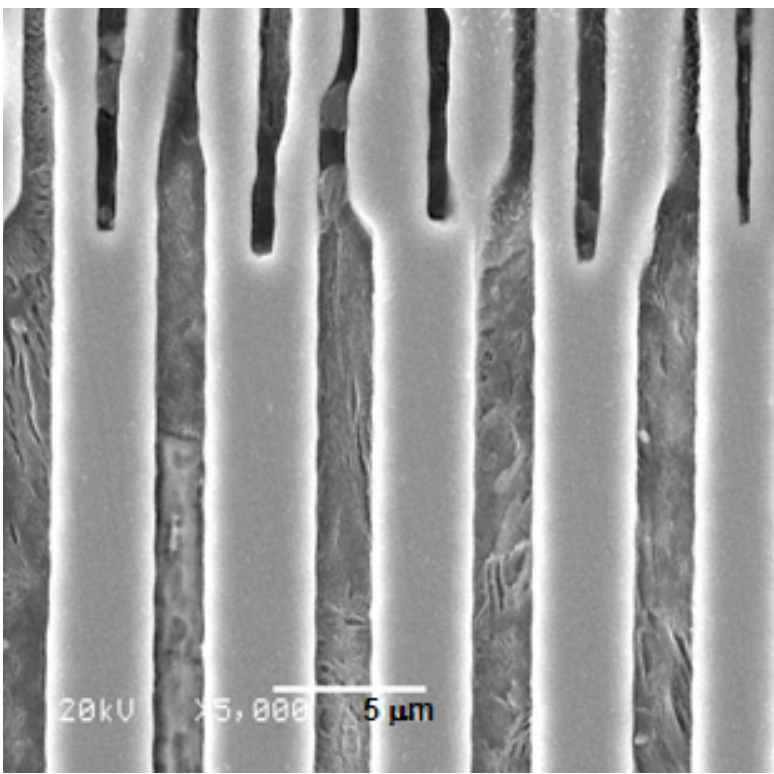

b)

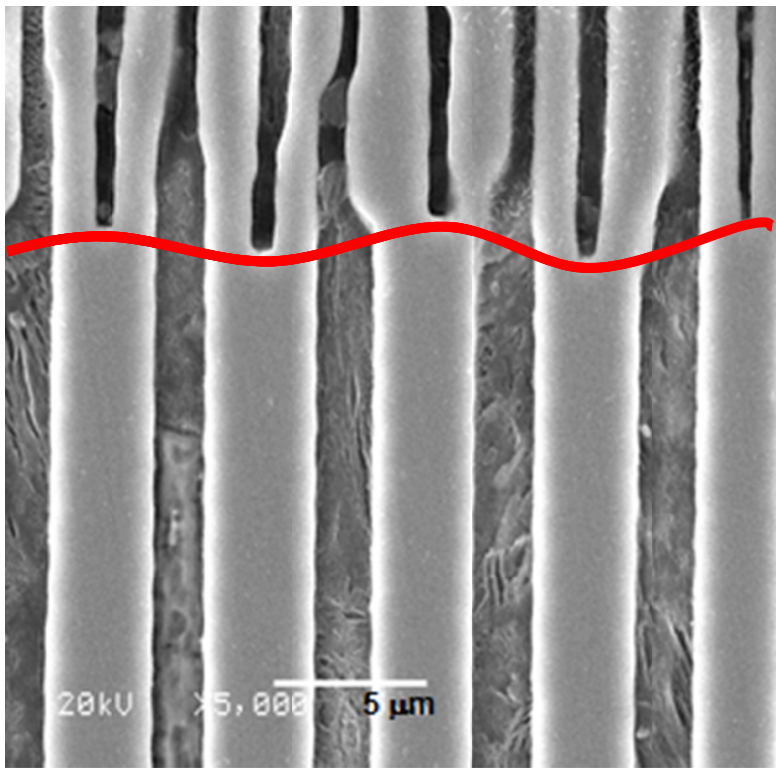

c)

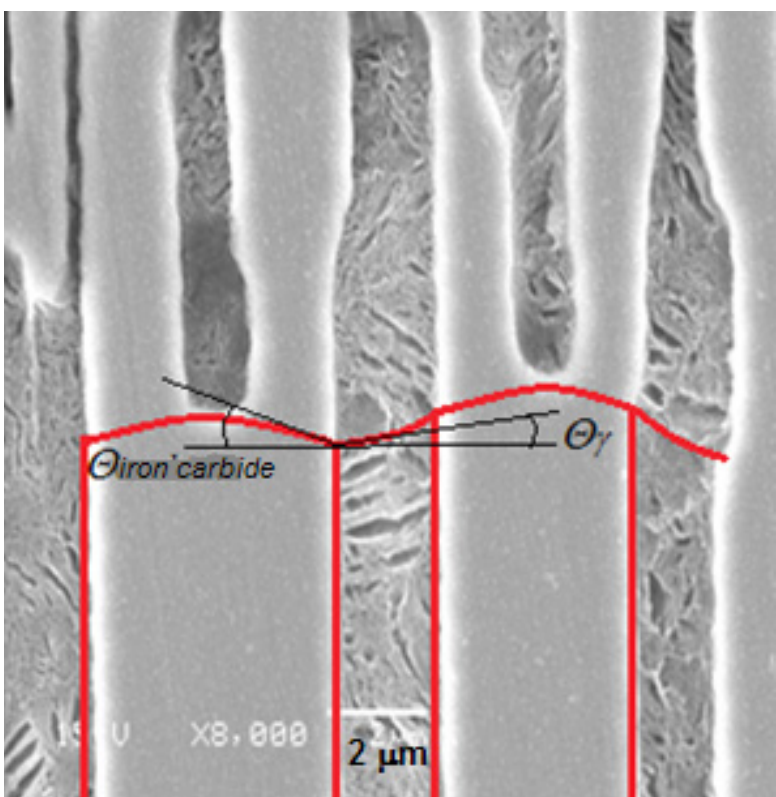

Fig. 6. SEM micrograph of white carbide eutectic, $v=125 \mu \mathrm{m} / \mathrm{s}$, $G=33.5 \mathrm{~K} / \mathrm{mm}$

\section{Acknowledgements}

The author wishes to express gratitude to Prof. E. Guzik, PhD E. Olejnik and $\mathrm{PhD}$ A. Janas from Faculty of Foundry Engineering, Department of Engineering of Cast Alloys and Composites at AGH in Cracow.

\section{REFERENCES}

[1] P. Magnin, R. Trivedi, Acta Metall. Mater. 39, 44, 453-467 (1991).

[2] R. Hu, X. Bi, J. Li, H. Fu, Interface morphology evolvement and microstructure characteristics of hypoetectic $\mathrm{Cu}-1,0 \mathrm{wt} \% \mathrm{Cr}$ alloy during unidirectional solidification, Science and Technology of Advanced Materials 6, 950-955 (2005).

[3] E. Guzik, A model of irregular eutectic growth taking as an example the graphite eutectic in Fe-C alloys. Dissertations Monographies 15, AGH Kraków (1994).

[4] E. Guzik., D. Kopyciński, Modelling structure parameters of irregular eutectic growth: Modification of Magnin-Kurz theory, Metallurgical and Mat. Trans. 37A, 3057-3067 (2006).

[5] V.L. Davies, Mechanism of crystallization in binary eutectic system, Journal of the Institute of Metals 93, 10-14 (1964-65).

[6] W. Wołczyński, Role of physical factors in solid - liquid interface formation during oriented eutectic growth, Crystal Research and Technology 25 (1), 1303-1309 (1990).

[7] W. Wołczyński, Contribution to transition layer determination for oriented eutectic growth, Crystal Research and Technology 25 (12), 1433-437 (1990).

[8] W. Wołczyński, Formation of concave-convex interface shape during oriented eutectic growth, Crystal Research and Technology 26 (2), 173-178 (1991).

[9] W. Wołczyński, Parabolic approximation to the shape of oriented eutectic interface, Crystal Research and Technology 27 (2), 195200 (1992).

[10] W. Wołczyński, Concentration micro-field for lamellar eutectic growth, Defect and Diffusion Forum 272, 123-138 (2007).

[11] W. Huang, L. Wang, Solidification researches using transparent model materials - A review, Science China Technological Sciences 55 (2), 377-386 (2012).

[12] L.E. Murr, E. Martinez, E.S. Gaytan, D.A. Ramirez, Contributions of light microscopy to contemporary materials characterization. The new directional solidification, Metallogr. Microstruct. Anal. 1, 45-58 (2012).

[13] K.A. Jackson, J.D. Hunt, Lamellar and rod eutectic growth, Transaction of the Metallurgical Society of AIME 236, 1129-1142 (1966).

[14] A.V. Catalina, P.W. Voorhees, R.H. Huff, A.L. Ganau, A model for eutectic growth in multicomponent alloys, IOP Conf. Series: Materials Science and Engineering 84012085 (2015).

[15] M. Trepczyńska-Łent, Possibilities of the materials properties improvement for the cementite eutectic by means of unidirectional solidification, Archives of Metallurgy and Materials 58 (3), 987991 (2013).

[16] M. Trepczyńska-Łent, XRD and EBSD measurements of directional solidification Fe-C eutectic alloy. Archives of Foundry Engineering 16 (4), 169-174 (2016). 